\title{
Biodiversity Studies of Insect Fauna of Ajmer order Diptera
}

\author{
Dr Rashmi Sharma and D. D. Sharma. \\ Dept. Of Zoology Spc Gca Ajmer Rajasthan India
}

\begin{abstract}
Ajmer is located in the center of Rajasthan (INDIA) between 25038 " and 26058 " north 75022 " east longitude covering a geographical area of about $8481 \mathrm{sq} \mathrm{km}$ hemmed in all sides by Aravalli hills . About 7 miles from the city is Pushkar lake created by the touch of lord Brahma. The Dargah of khawaja Moinuddin chisti is holiest shrine next to Mecca in the world. Ajmer is abode of certain flora and fauna that are particularly endemic to semi-arid and are specially adapted to survive in the dry waterless region of the state. Order Diptera comprise of flies two winged true flies hind wings reduced to balancing organ halters. Greek di two, ptera wings. Diptera comprise more than 900000 species.eg house fly, fruit fly, crane fly, mosquitoes etc. they have mobile head, compound eyes piercing and sucking mouth parts. Metamorphosis is complete, life cycle includes egg, larva, (3 instar stages), pupa and adult. Following Flies are recorded in AJMER.
\end{abstract}

Keyword: Ajmer, Faunal diversity, Diptera, Aravalis.

\section{Introduction}

Ajmer is located in the center of Rajasthan (INDIA) between 25038 " and 26058 " north Latitude and 73054 " and 75022 " east longitude covering a geographical area of about $8481 \mathrm{sq} \mathrm{km}$ hemmed in all sides by Aravalli hills. About 7 miles from the city is Pushkar lake created by the touch of lord Brahma. The Dargah of khawaja Moinuddin chisti is holiest shrine next to Mecca in the world. Ajmer is abode of certain flora and fauna that are particularly endemic to semi-arid and are specially adapted to survive in the dry waterless region of the state. Flies means two wings means two pairs of wings are present. Availability of flies were more during the day hours and population seemed to be Confined to the light areas. The order contains more species than any other order, constituting almost $25 \%$ of all known animal life-forms. About $40 \%$ of all described insect species are beetles (about 9,00000 species), and new species are discovered frequently. The largest taxonomic family, the culicidae, also belongs to this order.The diversity of flies very wide-ranging. They are found in almost all types of habitats, but are not known to occur in the polar region They interact with their ecosystem in several ways. They often feed on plants and animals, break down animal and plant debris, and eat other invertebrates . Some species are prey of various animals including birds and mammals. Certain species are agricultural pests, such as the plant-sucking insects that damage crops.

\section{Methodology}

Field observations were made during March to April and September to November in different areas of Ajmer East, West, North and South AJMER with varied habitats like houses, gardens, hilly areas parks mountains, vegetable areas, open fields, agricultural areas and other cultivated areas.

\section{Observations and Results}

During the course of present field investigations 12 families have been reported. The detail of Family, name of species and common name are given below .culicidae was found to be most dominant Super family, followed by family Muscidae species were found in all months except extreme winters i e December and January February. Some species were quick fliers others were shy in nature. Muscidae were the first to emerge (March) and Tephritidae was the most late arrival emerging in the month emerging in the month of April. The peak flies activity was observed in the month of July to October.

\section{Order Diptera}

Table:1 Flies of AJMER

\begin{tabular}{|l|l|l|l|l|}
\hline ssS. No. & Family/Scientific name & $\mathrm{M}$ & Abundance & Habitat \\
\hline 1 & $\begin{array}{l}\text { Nematocera } \\
\text { Chironomidae }\end{array}$ & $R s$ & $C$ & $T$ \\
\hline 2 & Culicidae & $R s$ & $C$ & $T$ \\
\hline 3 & Nymphomyidae & $R s$ & $C$ & $T$ \\
\hline 4 & Psychodidae & $R s$ & $C$ & $T$ \\
\hline 5 & Thaumaleidae & & $C$ & $T$ \\
\hline & Brachycera & $R s$ & $C$ & $T$ \\
\hline 7. & Calliphoridae & & $C$ & $T$ \\
\hline
\end{tabular}




\begin{tabular}{|l|l|l|l|l|}
\hline 8 & Chamaemyiidae & $R s$ & $C$ & $T$ \\
\hline 9 & Drosophilidae & $R s$ & $C$ & $T$ \\
\hline 10 & Muscidae & $R s$ & $C$ & $T$ \\
\hline 11. & Tephritidae & $R s$ & $C$ & $T$ \\
\hline 12. & Tabanidae & $R s$ & $C$ & $T$ \\
\hline
\end{tabular}

Rs- Resident, Sm- Summer visitor, Wm- Winter Visitor, C- common, F- Frequent, O- Ocassional, R- Rare, TTerrestrial, A-Aquatic.

\section{Discussion}

During the course of present field investigation, 12 species of flies were Observed.The detail list of family, name of species habitat, status, abundance is Provided. Culicidae was found to be most dominant Super family, followed by Super family Muscidae, followed by Tephritidae and then Psychididae followed by Calliphorodae. The present study reveals that Muscidae were the first to emerge (March) and Tephritidae was the most late arrival emerging in the month emerging in the month of April. The peak flies activity was observed in the month of July to October. There was no fly activity during peak summer (May, June) and peak winter (December January February). The overall flies activity was observed April during Day and September, October, November day .Depending upon weather, month, season, host plant temperature and type of species concerned.

\section{Conclusion}

The present field investigation revealed that district Ajmer is rich in floral and faunal Wealth. Specially in flies diversity. However its biological diversity not been documented till date. We can conclude that Diptera fauna of the area is increasing. The area needs to be continuosly monitored and efforts be made to document its unknown floral and faunal wealth and there is need to have a vision document on the sustainable development of the district care and focus on documentation and conservation of its rich biodiversity. The Aravallis are being continuously cut for house construction and urbanization. There should be a check on the activity. During the course of present field investigation, 180 families. The detail list of family, name of species habitat, status, abundance is provided. The present study reveals that 12 families were observed. Muscidae were the first to emerge (March) and Tephritidae was the most late arrival emerging in the month emerging in the month of April. The peak flies activity was observed in the month of July to October. There was no flies activity during peak summer (May, June) and peak winter (December January February). The overall flies activity was observed April during Day and September, October, November day .Depending upon weather, month, season, host plant temperature and type of species concerned.

\section{Acknowledgement}

We are thankful 1 to Principal SPC GCA for India and encouragement.

\section{References}

[1]. Order Diptera flies Bug Guide Iowa State University. Retrieved 26 May 2016

[2]. Comstock. John Henry 1949. An Introduction to Entomology Comstock Publicaton p 773.

[3]. Downes, William L. Jr Dahlem, Gregary A. (1987). Keys to the evolution of Diptera Role of Homoptera Environmental Evolution 16 (4) 847-854. 4. Wiegmann, Brian M. Yeates, David K (2007). Diptera true flies Tree and life web project Retrieved 27 May 2016. 